University of Wollongong

Research Online

Faculty of Engineering - Papers (Archive)

Faculty of Engineering and Information

Sciences

$1-1-2008$

\title{
Non-linear consolidation of soil with vertical and horizontal drainage under time-dependent loading
}

Xueyu Geng

Zhejiang University, xgeng@uow.edu.au

Follow this and additional works at: https://ro.uow.edu.au/engpapers

Part of the Engineering Commons

https://ro.uow.edu.au/engpapers/4979

\section{Recommended Citation}

Geng, Xueyu: Non-linear consolidation of soil with vertical and horizontal drainage under time-dependent loading 2008, 800-804.

https://ro.uow.edu.au/engpapers/4979

Research Online is the open access institutional repository for the University of Wollongong. For further information contact the UOW Library: research-pubs@uow.edu.au 


\title{
Non-linear Consolidation of Soil with Vertical and Horizontal Drainage under Time-dependent Loading
}

\author{
Xueyu Geng \\ College of Civil Engineering and Architecture, Zhejiang University, Hangzhou, 310027, China \\ College of Computer Science and Technology, Zhejiang University, Hangzhou, 310027, China \\ gengxy@gmail.com
}

\begin{abstract}
This paper presents a nonlinear theory for sand drain consolidation of clayey soils under time dependent loading. The solution is obtained using the method of separation of variables. Using the solutions obtained, some diagrams are prepared and the relevant consolidation behavior of soil with vertical and horizontal drainage under time-loadings is discussed. For nonlinear material properties, average degree of consolidation can be defined either in terms of settlement or in terms of effective stress. And consolidation will be slower when compared to the cases with constant material properties. And the difference depends on the external loading pressure $N_{\sigma}$, and the construction time $T_{v c}$.
\end{abstract}

\section{Introduction}

Good quality geologic materials for construction are becoming scare. Since compressible soils are usually characterized by very low permeability, the time needed for the desired consolidation can be long. Due to these reasons and become of the environmental restrictions on certain public works, ground improvement is becoming an essential part of infrastructure development. Hence, a system of vertical drains combined with vacuum preloading is an effective method to accelerate soil consolidation by promoting radial flow. For the classic vertical drain consolidation theory, a constant coefficient of volume compressibility, a constant coefficient of horizontal permeability and a constant coefficient of vertical permeability were assumed for given stress range[1-6]. However, for a relatively large applied stress range, it is known that both soil permeability and soil volume compressibility coefficients decrease as a result of physical reduction in void ratio during the consolidation process [7-10]. And pre-consolidation pressure is essential for predicting the actual settlement.
Otherwise, loads in the construction of civil engineering works are mostly applied gradually with time [11-12]. In many cases the loading process may endure over a long period of time, so a significant part of the consolidation occurs accordingly.

To the author's knowledge, however, no comprehensive solution to consolidation with both vertical and horizontal drainage including the non-line properties of soil and the changes of external loading is available in the literature. The content of this paper is specifically developed mathematical solutions with the idea that variable consolidation properties are particularly related to the aforementioned problems.

\section{Mathematical models for variable soil properties}

Here, take the $e-\log \sigma^{\prime}$ relationship which is used to determine the compressibility indices, and the $e-\log k$ relationship which is used to represent permeability variation linear responses into account to present the non-linear relationship of the soil.

Assuming that

$$
\begin{aligned}
& e-e_{0}=C_{c} \lg \left(\sigma_{0}^{\prime} / \sigma^{\prime}\right) \\
& e-e_{0}=C_{k} \lg \left(k_{v} / k_{v 0}\right) \\
& e-e_{0}=C_{h} \lg \left(k_{h} / k_{h 0}\right)
\end{aligned}
$$

where $e$ is the void ration, $e_{0}$ is the initial void ratio, $\sigma$, is the vertical total stress, $C_{c}$ is the compression index, $k_{v 0}$ is the vertical initial coefficient of permeability, $k_{h 0}$ is the horizontal initial coefficient of permeability, $C_{k}$ is the vertical hydraulic conductivity index, $C_{h}$ is the horizontal hydraulic conductivity index. Other assumptions are the same as Barron's.

Based on equations (1)-(3):

$k_{v}=k_{v 0}\left(\frac{\sigma_{0}^{\prime}}{\sigma^{\prime}}\right)^{C_{c} / C_{k}}$ 
$k_{h}=k_{h 0}\left(\frac{\sigma_{0}}{\sigma^{\prime}}\right)^{C_{h} / C_{k}}$

$m_{v}=-\frac{1}{1+e_{0}} \frac{\partial e}{\partial \sigma^{\prime}}=m_{v 0} \frac{\sigma_{0}^{\prime}}{\sigma^{\prime}}$

where $m_{v}$ is the coefficient of compressibility. $m_{v 0}=C_{c} /\left(1+e_{0}\right) / \ln 10 / \sigma^{\prime}$ is the initial coefficient of compressibility.

According to Terzaghi's Principle of effective stress, $\sigma$ 'can be expressed as:

$\sigma^{\prime}=q(t)+\sigma_{0}^{\prime}-u$

in which, $u$ is the pore water pressure, $q(t)$ is the external loading.

The analysis model is shown in Figure 1.

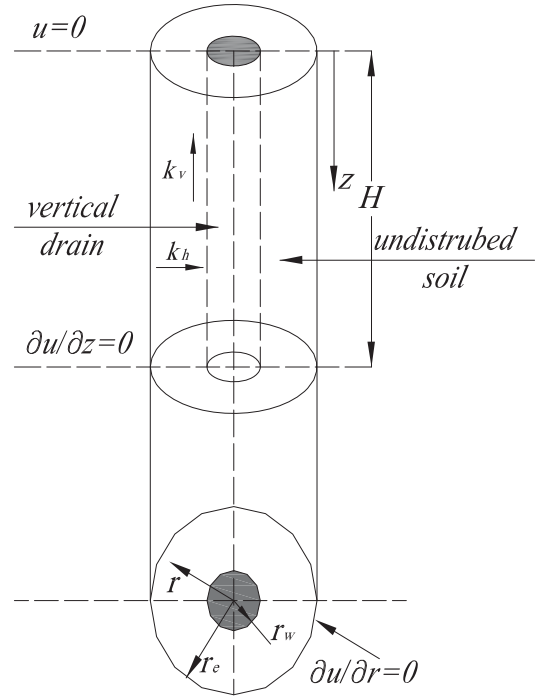

Fig.1 Scheme of ground with vertical drains

The differential equation for the dissipation of excess pore water pressure using the free strain assumption is

$\frac{1}{r \gamma_{w}} \frac{\partial}{\partial r}\left(r k_{h} \frac{\partial u}{\partial r}\right)+\frac{1}{\gamma_{w}} \frac{\partial}{\partial z}\left(k_{v} \frac{\partial u}{\partial z}\right)=-\frac{\partial \varepsilon_{v}}{\partial t}=m_{v}\left(\frac{\partial u}{\partial t}-\frac{d q}{d t}\right)$

where $r$ is the radial coordinate, $z$ is the vertical coordinate, $r_{e}$ is the radius of the equivalent cylindrical block of soil, $r_{w}$ is the radius of drain, $\gamma_{w}$ is the unit weight of water, $H$ is the drainage path.

Substituting Equations (4), (5) and (7) into Equation (8) yields:

$\frac{1}{r \gamma_{w}} \frac{\partial}{\partial r}\left[r k_{h 0}\left(\frac{\sigma_{0}^{\prime}}{\sigma}\right)_{c}^{C_{c} / C_{k}} \frac{\partial u}{\partial r}\right]+\frac{1}{\gamma_{w}} \frac{\partial}{\partial z}\left[k_{v 0}\left(\frac{\sigma_{0}^{\prime}}{\sigma^{\prime}}\right)^{C_{1} / C_{k}} \frac{\partial u}{\partial z}\right]=\frac{C_{c}}{\left(1+e_{0}\right) \ln 10} \frac{1}{\sigma}\left(\frac{\partial u}{\partial t}-\frac{d q}{d t}\right)(9)$

\section{Boundary and initial conditions}

The following commonly encountered boundary conditions are studied in this paper:

$\left\{\begin{array}{l}\sigma^{\prime}(r, 0, t)=q(t)+\sigma_{0}^{\prime},\left.\quad \frac{\partial \sigma^{\prime}}{\partial z}\right|_{z=H}=0 \\ \sigma^{\prime}\left(r_{w}, z, t\right)=q(t)+\sigma_{0}^{\prime},\left.\frac{\partial \sigma^{\prime}}{\partial r}\right|_{r=r_{e}}=0\end{array}\right.$

If drainage is available at the bottom of the sol, the drainage path $H$ is halved.

The initial condition is:

$$
\sigma^{\prime}(r, z, 0)=\sigma_{0}^{\prime}
$$

\section{Solutions for the governmental equation}

Equation (9) is non-linear in $\sigma^{\prime}$ and hence does not have a general solution with the boundary conditions mentioned above. Therefore, assuming the decrease in permeability is proportional to the decrease in compressibility during the consolidation of a soil and the distribution of initial effective pressures is constant with depth. Then,

$\frac{1}{r \gamma_{w}} \frac{\partial}{\partial r}\left[r k_{h 0}\left(\frac{\sigma_{0}^{\prime}}{\sigma^{\prime}}\right) \frac{\partial u}{\partial r}\right]+\frac{1}{\gamma_{w}} \frac{\partial}{\partial z}\left[k_{v 0}\left(\frac{\sigma_{0}^{\prime}}{\sigma^{\prime}}\right) \frac{\partial u}{\partial z}\right]=\frac{C_{c}}{\left(1+e_{0}\right) \ln 10} \frac{1}{\sigma}\left(\frac{\partial u}{\partial t}-\frac{d q}{d t}\right)$

By defining a new parameter

$\omega(z, r, t)=\ln \left(\frac{\sigma^{\prime}}{q(t)+\sigma_{0}^{\prime}}\right)$

Equation (12) can be simplified as follows:

$C_{h 0} \frac{1}{r} \frac{\partial}{\partial r}\left[r \frac{\partial \omega}{\partial r}\right]+C_{v 0} \frac{\partial^{2} \omega}{\partial z^{2}}=\frac{\partial \omega}{\partial t}-Q(t)$

in which,

$$
\begin{aligned}
& m_{v 0}=\frac{C_{c}}{\left(1+e_{0}\right) \sigma_{0}^{\prime} \ln 10}, C_{h 0}=\frac{k_{h 0}}{\gamma_{w} m_{v 0}}, C_{v 0}=\frac{k_{v 0}}{\gamma_{w} m_{v 0}}, \\
& Q(t)=-\frac{1}{\sigma_{0}^{\prime}+q(t)} \frac{d q}{d t}
\end{aligned}
$$

Using the method of separation of variables, the consolidation equation (14) under the given boundary and initial conditions in equations (11) and (12) can be solved.

Letting

$$
Z=z / H, N=\frac{r_{e}}{r_{w}}, L=\frac{C_{v 0} r_{w}^{2}}{C_{r 0} H^{2}}, R=r / r_{w}
$$

Here, $Z$ is a dimensionless vertical coordinate, $N$ is the ratio of the equivalent radius over well radius, and $L$ is a newly defined dimensionless parameter. $L$ is related to the vertical and horizontal consolidation coefficients $\left(C_{v 0}\right.$ and $\left.C_{h 0}\right)$, the radius of the well $\left(r_{w}\right)$ and the vertical drainage distance $(H)$. 
The solution to equation (14) becomes

$\omega=\sum_{m, n=1}^{\infty} A_{m n}(T) R_{m}(R) \sin \left(\lambda_{n} Z\right)$

in which $\lambda_{n}=\frac{2 n-1}{2} \pi$.

If $C_{v 0}$ is zero or $H$ is infinite, parameter $L$ is zero, which implies horizontal water flow and horizontal consolidation only. If $C_{h 0}$ is zero, $L$ is infinite, which implies vertical water flow and vertical consolidation only. If $r_{w}$ is zero, though $L$ is zero, but $N$ is infinite, this is a vertical consolidation case. The expressions for $A_{m n}, R_{m}$ and $\lambda_{n}$ in equation (14) are discussed as follows.

$R_{m}$ in equation (15) can be expressed in terms of Bessel function [13] of the first kind $\left(J_{0}, J_{1}\right)$ and of the second kind $\left(Y_{0}, Y_{1}\right)$ as follows:

$R_{m}(r)=Y_{1}\left(N \mu_{m}\right) J_{0}\left(\mu_{m} R\right)-J_{1}\left(N \mu_{m}\right) Y_{0}\left(\mu_{m} R\right)$

The quantity $\mu_{m}$ is the $m$ th positive root of the following equation:

$Y_{1}\left(N \mu_{m}\right) J_{0}\left(\mu_{m}\right)-J_{1}\left(N \mu_{m}\right) Y_{0}\left(\mu_{m}\right)=0$

$A_{m n}$ in equation (15) is given by:

$q(r, z, t)=q_{u} \quad(t \geq 0)(18)$

$A_{m n-c o n}\left(T_{v}\right)=\omega_{0} \cdot D_{m n}$

where, $\quad D_{m n}=\frac{B_{m n}}{\lambda_{n}} \exp \left(-\frac{\mu_{m}^{2}+\lambda_{m}^{2} L}{\mu_{1}^{2}+\lambda_{1}^{2} L} T_{v}\right)$;

$B_{m n}=\frac{4 r_{w} R_{m}^{\prime}\left(r_{w}\right) \pi^{2}}{4-\left[\pi r_{w} R_{m}^{\prime}\left(r_{w}\right)\right]^{2}}$

$r_{w} R_{m}^{\prime}\left(r_{w}\right)=\mu_{m}\left[Y_{1}\left(\mu_{m}\right) J_{1}\left(N \mu_{m}\right)-J_{1}\left(\mu_{m}\right) Y_{1}\left(N \mu_{m}\right)\right]$;

$T_{v}=\frac{\left(\mu_{1}^{2}+\lambda_{1}^{2} L\right) C_{h 0} t}{r_{w}^{2}}, \omega_{0}=\ln \frac{\sigma_{0}^{\prime}}{\sigma_{0}^{\prime}+q_{u}}=-\ln N_{\sigma}$,

$N_{\sigma}=1+\frac{q_{u}}{\sigma_{0}^{\prime}}, q_{u}$ is the final external loading increment.

\section{Examples and discussions}

It has been reported that the parameter $N$ is in the range of 5-80, and the value of parameter $L$ is in the range of $0-0.01$. Fig 2 shows that the excess pore water pressure $u$ and its rate of dissipation in such nonlinear consolidation is different from those in a linear consolidation. The bigger $N_{\sigma}$ is, the slower dissipation of excess pore water pressure is. However, the rate of settlement in a nonlinear consolidation subjecting to the assumptions made here is no different from that in a linear consolidation, which is the same as Zhu's result. Because the nonlinear character of the soil considered in this paper, the decrease in permeability is proportional to the decrease in compressibility during the consolidation and the distribution of initial effective pressures is constant with depth, there should be no different from the situation in linear consolidation in theory. At the same time, it is proved from the theory that the results in this paper are correct.
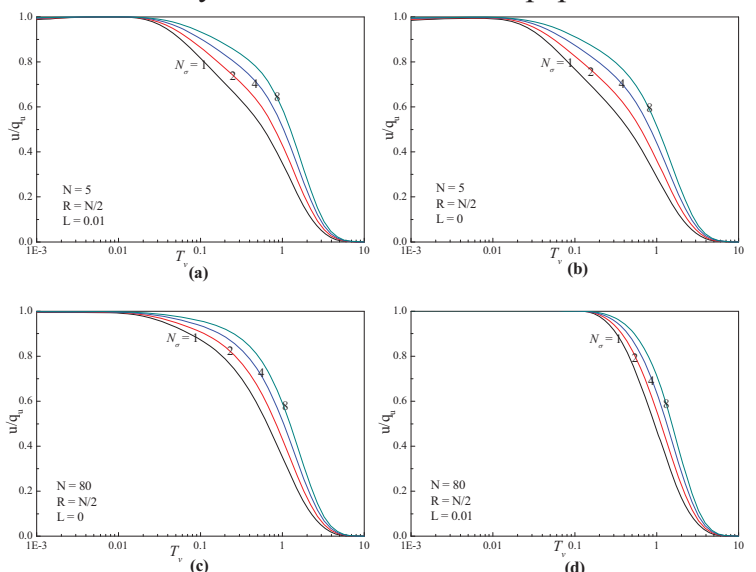

Fig. 2 Dissipation of pore pressure at bottom under the constant loading

For the same time factor $T_{v}, N$ and $L$ are the two main factors affect the degree of consolidation defined by the settlement. For the range of $5 \leq N \leq 80,0 \leq L \leq 0.01$, the maximum difference deviation is only $13.1 \%$. This indicates that the relationship between the degree of consolidation with the time factor $T_{v}$ is approximately independent of the dimensionless parameters $N$ and $L$ [12].
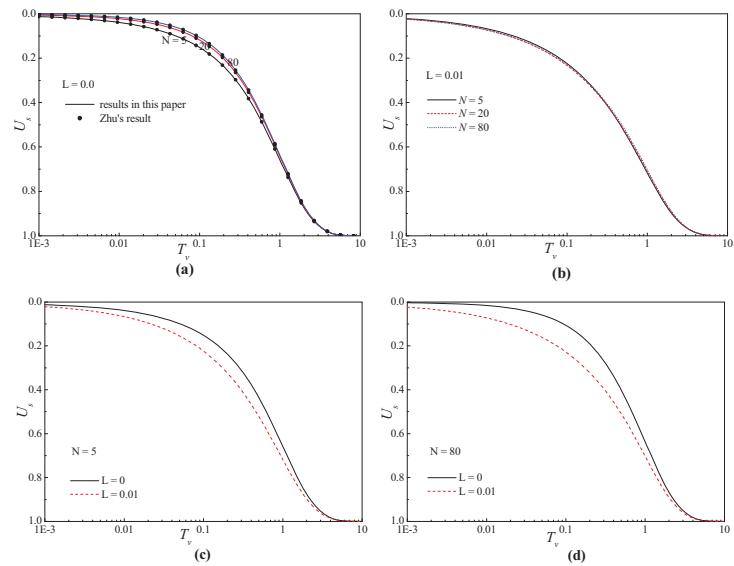

Fig. 3 Degree of consolidation defined in terms of settlement under the constant loading 
In such nonlinear consolidation the degree of consolidation defined by the excess pore water pressure is different from in a linear consolidation, which as Figure 4 shows. It can be seen that the difference will disappear as the value of $N_{\sigma}$ reproaches to 1 . It also can be approved by mathematic method.

Since the value of $N_{\sigma}$ reflects the magnitude of load, it can be concluded that the discrepancy between linear and nonlinear consolidation is greatly related to the level of the external load level, and the smaller the load level, the smaller the discrepancy. When $N_{\sigma}=12$, the maximum difference deviation of $U_{p}$ will almost reach $15 \%$ (as Figure 4 shows). Therefore, the nonlinear character of the soil should be considered when the external loading is big. In figure 5 and figure 6 , curves of the average degree of consolidation $U_{p}$ and $U_{s}$ versus time factor $T_{v}$ are given, respectively. With the increasing of the load level $N_{\sigma}$, the difference of $U_{p}$ and $U_{s}$ between the current solution and the line's solution gets bigger. Moreover, for the same parameters, $U_{p}$ is always less than $U_{s}$.

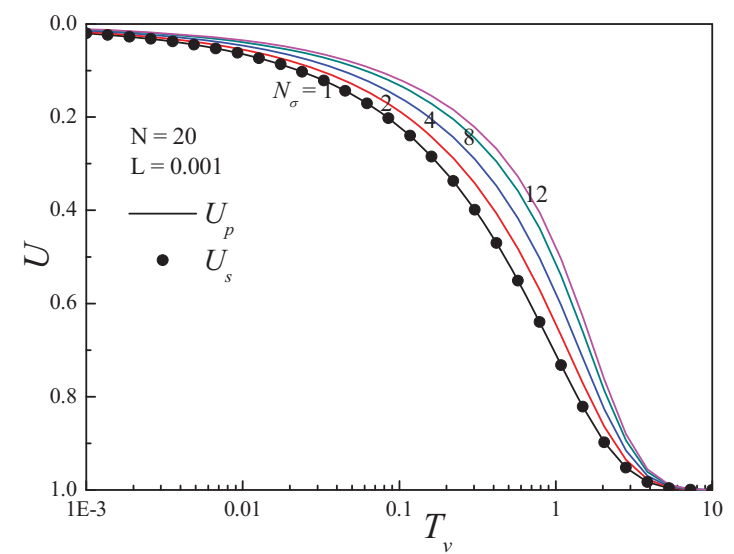

Fig. 4 Comparison between $U_{p}$ and $U_{s}$ under the constant loading

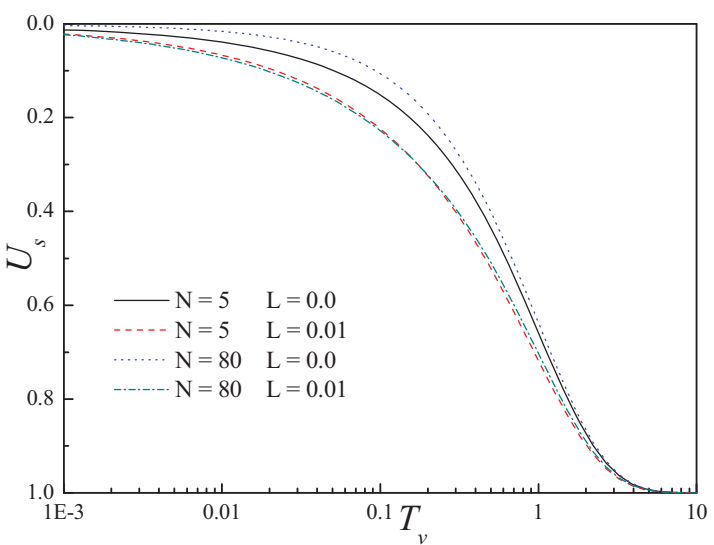

Fig. 5 Degree of consolidation defined in terms of settlement for different $N$ and $L$ under the constant loading

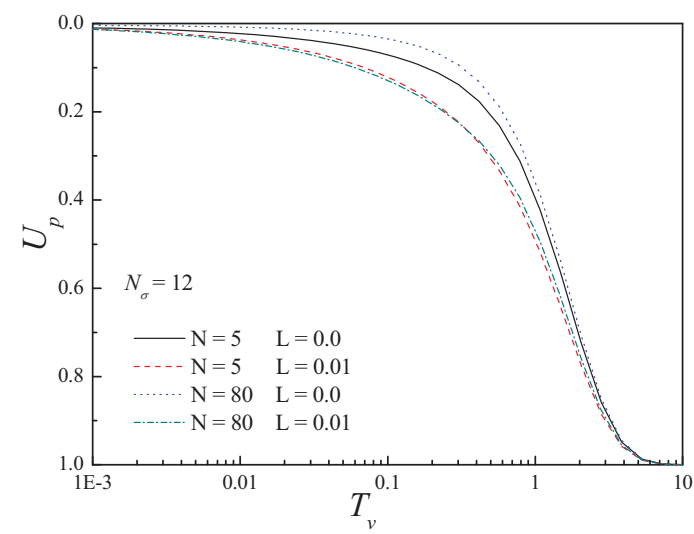

Fig. 6 Degree of consolidation defined in terms of effective stress for different $\mathrm{N}$ and $\mathrm{L}$ under the constant loading

\section{Conclusion}

The developed method in this paper can handle the problem of non-linear consolidation with vertical and horizontal drainage undergoing time-dependent loadings.

1) The equations presented given an analytical solution to consolidation of soil with vertical and horizontal drainage under time-dependent loading.

2) Because of the nonlinear character of the soil, the average degree of consolidation can be defined either in terms of settlement $\left(U_{s}\right)$ or in terms of effective stress $\left(U_{p}\right)$. While the former shows the rate of settlement development, the later indicates the rate of the increase of effective pressure or the rate of the dissipation of excess pore water pressure. And for the same parameters, $U_{p}$ is always less than $U_{s}$. 
3) The average degree of consolidation defined in terms of settlement $U_{s}$ in non-linear theory has no different with the average degree of consolidation in linear theory for the constant loading case. It means that the rate of settlement in a nonlinear consolidation with vertical and horizontal drainage is no different from that in a linear consolidation when the soil subjected to constant loading.

4) Since the value of $N_{\sigma}$ reflects the magnitude of load, it can be concluded that for the constant loading case the discrepancy between linear and nonlinear consolidation is greatly related to the level of the external load level, and the smaller the load level, the smaller the discrepancy.

5) For the ramp loading case, the discrepancy between linear and nonlinear consolidation is related not only to the external load level $N_{\sigma}$, but also the construction time factor $T_{v c}$.

\section{References}

1. Barron, R. A.: Consolidaiton of Fine-grained Soils by Drain Wells. Trans. ASCE 113, No. 2346 (1948) 718-742

2. Horne, M. R.: The Consolidation of a Stratified Soil with Vertical and Horizontal Drainage. Int. J. Mech. Sci. 6(1964) 187-197

3. Yoshikuni, H. and Nakanodo, H.: Consolidation of 'Soils by Vertical Drain Wells with Finite Permeability. Soils Found. 14, No. 2.(1974) 35-46

4. Olson, R. E.: Consolidation under Time-dependent Loading. J. Geotech. Engng Div., ASCE. 103. No. GT1 (1977) 55-60

5. Basak, P. and Madhav, M. R.: Analytical Solutions of Sand Drain Problem. Journal of Geotechnical engineering ASCE, 104(GT1) (1978) 129-135
6. Tang, X. W. and Onitsuka, K.: Consolidation of Ground with Partially Penetrated Vertical Drains. Geotechnical Engineering Journal, 29, No. 2. (1998) 209-231

7. Davis, R. E. and Raymond, G. P.: A Non-linear of Consolidation. Geotechnique. 15, No. 2. (1965) 161-173

8. Xie, K. H., Xie, X. Y. and Jiang, W.: A Study on One-dimensional Nonlinear consolidation of double-layered Soil. 29 (2002) 151-168

9. Geng, X. Y., Cai, Y. Q. and Xu, C. J.: Non-linear Consolidation Analysis of Soil with Variable Compressibility and Permeability under Cyclic Loadings. Int. J. Numer. Anal. Meth. Geomech. 30 (2006) 803-821.

10.Cai, Y. Q., Geng, X. Y. and Xu, C. J.: Solution of One-dimensional Finite-strain Consolidation of Soil with Variable Compressibility under Cyclic Loadings. Computers and Geotechnics. 34 (2007) 31-40.

11.Lekha, K. R., Krishnaswamy, N. R. and Basak, P.: Consolidation of Clay by Sand Drain under Timedependent Loading. J. Geo. Geoen. Engine. ASCE, 124, No. 1. (1998) 91-94

12.Zhu, G. and Yin, J. H.: Consolidation of Soil with Vertical and Horizontal Drainage under Ramp Load. Geotechnique 51. No. 4. (2001) 361-367

13.Moshier, S. L. B, Methods and programs for mathematical functions. Chichster: Ellis Horwood, 1989 